\title{
Bacterial metabolism of side chain fluorinated aromatics: cometabolism of 4-trifluoromethyl(TFM)-benzoate by 4-isopropylbenzoate grown Pseudomonas putida JT strains*
}

\author{
Karl H. Engesser ${ }^{1}$, Miguel A. Rubio ${ }^{2}$, and Douglas W. Ribbons ${ }^{3}$ \\ ${ }^{1}$ Institut für Mikrobiologie der Universität Stuttgart, D-7000 Stuttgart 1, Federal Republic of Germany \\ 2 Abteilung für Gewässerreinigungstechnik, Technische Universität Hamburg-Harburg, D-2100 Hamburg 90, Federal Republic of Germany \\ ${ }^{3}$ Centre for Biotechnology, Imperial College of Science and Technology, London SW72AZ, UK
}

\begin{abstract}
Enzymes of the p-cymene pathway in Pseudomonas putida strains cometabolized the intermediate analogue 4-trifluoromethyl(TFM)benzoate. Three products, 4-TFM2,3-dihydro-2,3-dihydroxybenzoate, 4-TFM-2,3-dihydroxybenzoate and 2-hydroxy-6-oxo-7,7,7-trifluorohepta-2,4dienoate (7-TFHOD) were identified chemically and by spectroscopic properties.

Certain TFM-substituted analogue metabolites of the p-cymene pathway were transformed at drastically reduced rates.

Hammett type analysis of ring cleavage reactions of 4-substituted 2,3-dihydroxybenzoates revealed the negative inductive and especially mesomeric effect of substituents to be rate determining. Whereas decarboxylation of 3-carboxy7-TFHOD was not affected by fluorine substitution the subsequent hydrolysis of 7-TFHOD proceeded very slowly. The negative inductive effect of the TFM-group probably inhibited heterolysis of the carbon bond between $\mathrm{C}_{5}$ and $\mathrm{C}_{6}$ of 7-TFHOD.
\end{abstract}

Key words: Cymene pathway - Side chain fluorinated aromatics - Cometabolism - Pseudomonas putida JT 2-Hydroxy-6-oxohepta-2,4-dienoate hydrolase (2-hydroxymuconic semialdehyde hydrolase)

The metabolism of fluorinated benzoates by bacteria has been thoroughly investigated (Harper and Blakley 1971; Smith et al. 1968; Ali et al. 1962; Milne et al. 1968; Husain et al. 1980; Clarke et al. 1975; Goldman et al. 1967). Side chain fluorinated aromatics the commonest of which are trifluoromethyl-substituted, however, have been studied to a much lesser extent (DeFrank and Ribbons 1976). In the preceeding paper (Engesser et al. 1988) evidence was pre-

\footnotetext{
Abbreviations: DHB, 1,2-Dihydroxy-2-hydrobenzoate; DHC, 2,3Dihydro-2,3-dihydroxybenzoate, this compound was termed DHC simply to distinguish it from the similar 1,2-dihydroxy-2-hydrobenzoate (DHB) as described in the preceeding paper (Engesser et al. 1988); HMS, 2-Hydroxymuconic semialdehyde; HOD, 2Hydroxy-6-oxohepta-2,4-dienoate; 7-TFHOD, 2-Hydroxy-6-oxo7,7,7-trifluorohepta-2,4-dienoate; TFM, Trifluoromethyl

* This work was supported, in part, by the Gesellschaft für Strahlen- und Umweltforschung, Neuherberg/München, FRG

Offprint requests to: $\mathrm{K}$. H. Engesser
}

sented that side chain fluorination of methylbenzoate severely impeded its catabolism in Pseudomonas putida $\mathrm{mt}-2$ and Rhodococcus rubropertinctus N657. Neither of the three isomeric trifluoromethyl (TFM) substituted benzoates could serve as a growth substrate for these strains. With the aim of broadening our knowledge concerning the bacterial catabolism of side chain fluorinated aromatics it seemed therefore worthwhile to examine their utilization by p-cumate (4-isopropylbenzoate) degrading organisms. 4-Isopropylbenzoate is dissimilated via a pathway (Fig. 1) in Pseudomonas putida JT strains involving 2,3-dihydroxylation of the benzoate nucleus compared with 1,2-dioxygenation of 3-methylbenzoate coded by TOL-plasmid bearing strains (DeFrank and Ribbons 1977a). Both pathways, however, converge at the stage of the hydrolase substrate (DeFrank and Ribbons 1977b).

Therefore it was of interest to examine the specificity of the p-cymene pathway enzymes towards trifluoromethyl substituted substrate analogues, of which 4-trifluoromethylbenzoate had been shown to be metabolized to a 2,3-dihydrodiol by a mutant of Pseudomonas putida (DeFrank and Ribbons 1976).

\section{Materials and methods}

Chemicals. The isomeric trifluoromethylbenzoates were obtained from Bayer AG, Leverkusen, FRG. 4-Isopropylbenzoate (p-cumate) was produced from 4-isopropylbenzaldehyde (Meyer 1883). $177 \mathrm{~g}$ 4-Isopropylbenzaldehyde and $200 \mathrm{~g} \mathrm{NaOH}$ were mixed with $700 \mathrm{ml} \mathrm{H}_{2} \mathrm{O} .175 \mathrm{~g} \mathrm{KMnO}_{4}$ in $4 \mathrm{IH}_{2} \mathrm{O}$ were added stepwise. The solution was stirred at room temperature until the reaction was finished (monitored by HPLC). Excess of permanganate was destroyed with methanol. After filtration with a Büchner funnel the product was precipitated with sulfuric acid and recrystallized from water/ethanol. The melting point was $119^{\circ} \mathrm{C}\left(\right.$ Lit. $\left.118^{\circ} \mathrm{C}\right)$. The yield was $45 \%$ of starting material.

All other benzoates were bought from Aldrich Chemical Company, Steinheim, FRG. 4-Isopropyl-2,3-dihydro-2,3dihydroxybenzoate (4-isopropyl-DHC) was produced from 4-isopropylbenzoate employing the mutant Pseudomonas putida JT 832 (DeFrank and Ribbons 1976, 1977a; Wigmore and Ribbons 1980). The isolated product still contained about 4\% (by weight) 4-isopropyl-3-hydroxybenzoate. This latter compound was accessible in pure form after acid catalyzed rearomatization of 4-isopropyl-DHC. $\mathrm{R}_{\mathbf{f}}$-value 


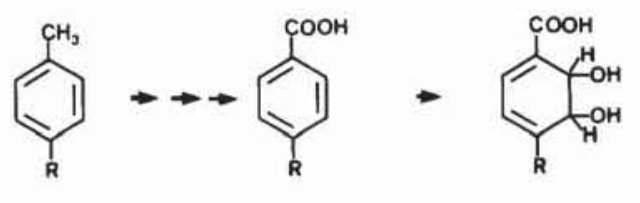

$\downarrow$

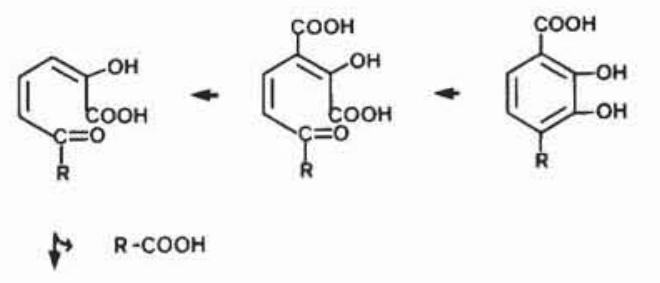

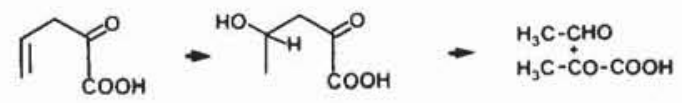

Fig. 1. Pathway of p-isopropylbenzoate (cumate) and p-ethylbenzoate ( $\mathrm{R}=$ isopropyl and ethyl rsp.) degradation in Pseudomonas putida JT101 and JT811

with solvent system I on preparative TLC plates was 0.69 . There was no fluorescence at $\lambda=366 \mathrm{~nm}$ i.e. no simultaneously produced 4-isopropyl-2-hydroxybenzoate. 4-Trifluoromethyl-2,3-dihydro-2,3-dihydroxybenzoate was produced with the mutant Pseudomonas putida JT107. The sodium salt of this compound was purified by repeated crystallization (water/propanol). The rearomatization product 4-trifluoromethyl-3-hydroxybenzoate $\left(\mathrm{R}_{\mathrm{F}}\right.$-value on TLC plates with solvent system I was 0.72 ) was not detected in the sample.

4-Methyl-2,3-dihydroxybenzoate was prepared according to a procedure described for the preparation of resorcinylic acid (Wessely et al. 1950). On TLC plates a major impurity with a $R_{r}$-value of 0.52 (solvent system $I$ ) was separated from the product $\left(\mathrm{R}_{\mathrm{f}}\right.$-value $\left.=0.79\right)$. After further purification on TLC plates (solvent system trichloromethane/methyl ethyl ketone/methanol; $60 / 26 / 40$ by vol.) the parental ion at $\mathrm{m} / \mathrm{e}=168$ could be observed in a mass spectrum. For characterization purposes 4-methyl-2,3dihydroxybenzoate had to be produced also biologically using the mutant Pseudomonas putida JT833 but the turnover of 4-methylbenzoate by this strain was incomplete. TLC purification (trichloromethane/methanol/acetic acid; 9/3/1 by vol.) and sublimation of the product yielded pure sample. In a mass spectrum a parent ion of $\mathrm{m} / \mathrm{e}=168$ was observed with further fragmentations being at $\mathrm{m} / \mathrm{e}=150$ (loss of water) and $\mathrm{m} / \mathrm{e}=122$ (additional loss of CO). In a $100 \mathrm{MHz}$ NMR spectrum resonances at $\delta=2.26 \mathrm{ppm}(3 \mathrm{H}, \mathrm{s}) \delta=$ $6.7(1 \mathrm{H}, \mathrm{d}, \mathrm{J} 8.4 \mathrm{~Hz})$ and $7.3(1 \mathrm{H}, \mathrm{d}, \mathrm{J} 8.4 \mathrm{~Hz}$ ) were observed consistent with a methyl group and two vicinal protons respectively.

4-Isopropyl-2,3-dihydroxybenzoate was produced biologically with the mutant Pseudomonas putida JT833. After complete turnover of 4-isopropylbenzoate, the product was sublimed immediately after extraction and evaporation of solvent. There were no impurities as judged by TLC and
Table 1. Strains of Pseudomonas putida used

\begin{tabular}{|c|c|c|c|}
\hline Strain & Genotype & Phenotype & Reference \\
\hline \multicolumn{2}{|c|}{$\begin{array}{l}\text { JT101 (for- } \\
\text { merly PL-W) }\end{array}$} & $\mathrm{Cym}^{+}, \mathrm{Cum}^{+}$ & $\begin{array}{l}\text { DeFrank and } \\
\text { Ribbons 1977a }\end{array}$ \\
\hline JT104 & Cym K-71 & $\mathrm{Cym}^{-}, \mathrm{Cum}^{-}$ & $\begin{array}{l}\text { DeFrank and } \\
\text { Ribbons } 1977 b\end{array}$ \\
\hline JT107 & Cym I-5I & $\mathrm{Cym}^{-}, \mathrm{Cum}^{-}$ & $\begin{array}{l}\text { DeFrank and } \\
\text { Ribbons 1976, } \\
1977 \text { a }\end{array}$ \\
\hline JT811 & Cym R-1 & $\begin{array}{l}\mathrm{Cym}^{+}, \\
\mathrm{Cum}^{+}, c\end{array}$ & $\begin{array}{l}\text { Wigmore and } \\
\text { Ribbons } 1980\end{array}$ \\
\hline JT832 & Cym R-1, Cym I-3 & $\begin{array}{l}\mathrm{Cym}^{-}, \\
\text {Cum }^{--}, c\end{array}$ & $\begin{array}{l}\text { Wigmore and } \\
\text { Ribbons } 1980\end{array}$ \\
\hline JT833 & Cym R-1, Cym J-4 & $\begin{array}{l}\text { Cym }^{-}, \\
\text {Cum }^{-}, c\end{array}$ & $\begin{array}{l}\text { Wigmore and } \\
\text { Ribbons } 1980\end{array}$ \\
\hline
\end{tabular}

$c$ Constitutive

HPLC. In the mass spectrum a parental ion of $\mathrm{m} / \mathrm{e}=196$ was observed with further fragmentation being at $\mathrm{m} / \mathrm{e}=$ 178 (loss of $\mathrm{H}_{2} \mathrm{O}$ ) and $\mathrm{m} / \mathrm{e}=150$ (additional loss of $\mathrm{CO}$ ). The most abundant peak at $\mathrm{m} / \mathrm{e}=163$ results from loss of $\mathrm{H}_{2} \mathrm{O}$ and methyl radical. The NMR spectrum gave resonances at $\delta=1.25 \mathrm{ppm}(6 \mathrm{H}, \mathrm{d}), \delta=3.4 \mathrm{ppm}(1 \mathrm{H}, \mathrm{m}), \delta=$ $6.8(1 \mathrm{H}, \mathrm{d}, \mathrm{J} 8.5 \mathrm{~Hz})$ and $\delta=7.4(1 \mathrm{H}, \mathrm{d}, \mathrm{J} 8.5 \mathrm{~Hz})$ which are consistent with an isopropyl substituent and two adjacent aromatic protons. For characterization and preparation of 3-trifluoromethyl(TFM)-catechol, 2-hydroxy-6-oxo-hepta2,4-dienoate, 2-hydroxy-7-methyl-6-oxo-octa-2,4-dienoate and 2-hydroxy-6-oxo-7,7,7-trifluoro-hepta-2,4-dienoate (7TFHOD) see preceeding paper (Engesser et al. 1988).

Chemicals for media were of the highest grade commercially available.

Organisms. Strains descriptions are given in Table 1.

For description of growth conditions, chromatographical and spectroscopical methods see preceeding paper (Engesser et al. 1988).

Isolation and derivatization of metabolites. Extraction procedures were described previously (Hartmann et al. 1979). Methylesters were prepared using N-methyl-N-nitroso-ptoluenesulfonamide (DeBoer and Backer 1954). If necessary, the reaction was followed by analytical TLC.

Enzyme assays. P-Cumate dioxygenase was assayed using whole cells (Reineke and Knackmuss 1978a). 2,3-Dihydro2,3-dihydroxybenzoate(DHC)-dehydrogenase was measured according to previously published procedures (Reineke and Knackmuss 1978b) with the exception that $50 \mathrm{mM}$ phosphate buffer ( $\mathrm{pH}$ 7.4) was used. The exact concentrations of dienediol salts were estimated by calculating the amount of $\mathrm{NaDH}$ at $\lambda=366 \mathrm{~nm}$ produced after complete substrate turnover using a crude extract of the mutant JT833 dialyzed $(15 \mathrm{~h})$ against $50 \mathrm{mM}$ phosphate buffer $(\mathrm{pH} 7.4)$. 2,3-Dihydroxybenzoate-3,4-dioxygenase was assayed according to literature (DeFrank and Ribbons 1977b) using the mutant strain JT104, which prevents further metabolism of products. The extinction coefficient used was $\varepsilon=21.600$ for 3-carboxy-2-hydroxy-7-methyl-6-oxo-octa-2,4-dienoate. The corresponding $\lambda_{\max }$ value was $345 \mathrm{~nm} .3$ - Carboxy - 2hydroxy-7-methyl-6-oxo-octa-2,4-dienoate-decarboxylase 
was assayed as described (DeFranc and Ribbons 1977b). For extinction coefficients see the test for 2,3-dihydroxybenzoate-3,4-dioxygenase. 2-Hydroxy-6-oxo-hepta-2,4-dienoate(HOD)-hydrolase was measured by following the decrease of absorption at respective $\lambda_{\max }$ values of substituted HOD analogues (DeFrank and Ribbons 1977b). The crude extracts from JT101 and JT104 were dialyzed against $50 \mathrm{mM}$ phosphate buffer ( $\mathrm{pH}$ 7.4). For extinction coefficients see also preceeding paper (Engesser et al. 1988).

\section{Results}

Production and identification of analogue metabolites

As in the case of Pseudomonas putida mt-2 (Engesser et al. 1988 ) the trifluoromethyl(TFM)-benzoates did not serve as growth substrates for the $p$-cumate utilizing Pseudomonas putida JT strains. In contrast to Pseudomonas putida $\mathrm{mt}-2$, however, induction of the alkylbenzoate degrading enzymes by 4-TFM-benzoate could be observed (De Frank and Ribbons 1976, 1977a, b).

Resting cells of $p$-cumate (4-isopropylbenzoate) grown Pseudomonas putida JT101 showed only low turnover rates for TFM-benzoates. Using exponentially growing cells, however, moderate transformation of 4-TFM-benzoate occurred, whereas the 2- and the 3-isomere were attacked only very slowly. The turnover of 4-TFM-benzoate had already been demonstrated (De Frank and Ribbons 1976) with cells of Pseudomonas putida JT101 growing with glucose and incubated with this side chain fluorinated analogue during exponential growth phase.

When a cell suspension (cumate grown) of high optical density $\left(\mathrm{OD}_{546}=15\right)$ was divided and incubated with $p$-cumate $(3.3 \mathrm{mM})$ as control and a mixture of $p$-cumate and 4-TFM-benzoate ( $3.3 \mathrm{mM}$ each), no influence of the latter substrate on turnover rate of $p$-cumate could be observed. This demonstrates the poor binding of the side chain fluorinated substrate 4-TFM-benzoate to the cumate dioxygenase. Glucose-grown cells of Pseudomonas putida JT101 induced for cumate degrading enzymes transformed 4-TFMbenzoate incompletely. TLC analysis (solvent system I) of the culture supernatant revealed the presence of three metabolites. The most polar metabolite J1 had an $\mathrm{R}_{\mathrm{f}}$-value of 0.29 . A yellow metabolite $\mathrm{J} 2$ migrated with an $R_{\mathrm{r}}$-value of 0.37 to 0.4 , and metabolite $\mathrm{J} 3$ was located at $\mathrm{R}_{\mathrm{f}}$-value of 0.73 . The structure of metabolite $\mathrm{J} 1$ could be assigned most easily using a mutant of Pseudomonas putida JT101, strain JT107 which accumulates the dihydrodiols from 4-substituted benzoates (DeFrank and Ribbons 1976, 1977a). Using HPLC, metabolite J1 eluted with the biologically prepared 4-trifluoromethyl-2,3-dihydro-2,3-dihydroxybenzoic acid (retention volumes with solvent system AI $+25 \%$ BII: $3.3 \mathrm{ml}$ and $100 \%$ AI: $16.5 \mathrm{ml}$, see Materials and methods). Maximum absorption measured in situ was found for both compounds to be $\lambda=275 \mathrm{~mm}$ (phosphate buffer, $50 \mathrm{mM}$, $\mathrm{pH} 7.5$ ). Metabolite J1 as well as the reference dihydrodiol from the mutant JT107 showed the same chemical rearomatization characteristics and could be hydrolyzed subsequently to hydroxyterephthalic acid. This can be expected to happen with trifluoromethyl-substituted aromatic compounds bearing at least one ortho-hydroxyl group (Engesser et al. 1988). According to a previously made suggestion (DeFrank and Ribbons 1976) 3-hydroxy-4-TFMbenzoate was deduced to be the correct structural assign-

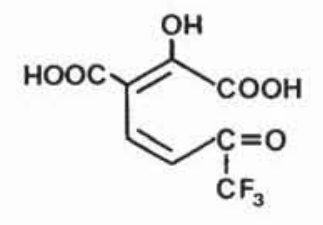

a
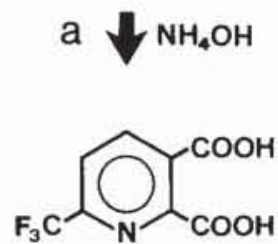

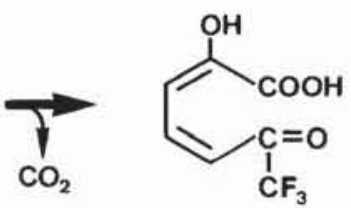

b $\checkmark \mathrm{NH}_{4} \mathrm{OH}$

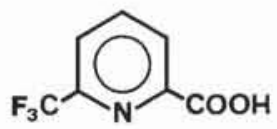

Fig. 2a, b. Possible species of TFM-picolinic acids produced by cyclization of 2-hydroxy-6-oxo-7,7,7-trifluoro-hepta-2,3-dienoic acid (b) or its 3-carboxy derivative (a). For conditions of cyclization in aqueous solutions of ammonia see Materials and methods

ment instead of the 2-hydroxy isomere. This was based on the failure to detect any fluorescence of rearomatization products of 4-TFM-2,3-dihydro-2,3-dihydroxybenzoates.

Spectroscopic characteristics in acidic and basic solution suggested metabolite $\mathrm{J} 2$ to have a muconic acid semialdehyde chromophore. According to Fig. 1 and Fig. 2 two alternative structures had to be considered for the compound $\mathbf{J} 2$. After cyclization in the presence of ammonia, J2 was purified on TLC plates and methylated (see Materials and methods). One of the possible pyridine derivatives, 6-TFM-2,3-dicarboxypyridine would be likely to loose the carboxyl group attached to C-2 as was found for 2,3dicarboxypyridine (Bialek 1962), yielding a nicotinic acid derivative. So even after decarboxylation of 6-TFM-2,3dicarboxylic acid the resulting 6-TFM-3-carboxypyridine would be clearly distinguishable from directly generated 6-TFM-2-carboxypyridine.

HPLC analysis using an authentic probe (Engesser et al. 1988) clearly identified the derivatized metabolite J2 to be the methylester of 6-TFM-2-carboxypyridine. $\left(\lambda_{\max }\right.$ measured in situ at a solvent mixture of $\mathrm{AI} / 40 \%$ BII were in each case 213 and $261 \mathrm{~nm}, \lambda_{\min }$ was $236 \mathrm{~nm}$ ). Metabolite $\mathrm{J} 2$ therefore is not attributable to a 3-carboxy-derivative of 2-hydroxy-6-oxo-7,7,7-trifluoro-hepta-2,4-dienoate (7TFHOD) but to the decarboxylated intermediate 7-TFHOD itself.

Analysis of product excretion patterns of mutants of the cymene pathway gave first hints concerning the structure of metabolite J3. Firstly, a mutant defective in dihydrodiol dehydrogenase (PpJT 832) did not produce metabolite J3 during incubation with a mixture of glucose and 4-TFMbenzoate. Secondly, a mutant unable to metabolize the ring fission product of 2,3-dihydroxybenzoates, strain JT104 accumulated metabolite $\mathrm{J} 3$ showing the same time dependence of excretion as the wild type. Finally, UV-absorption maxima were similar to 4-TFM-3-hydroxybenzoate (data not shown). These preliminary results strongly suggested metabolite J3 to have the structure 4-TFM-2,3-dihydroxybenzoate.

To obtain sufficient amounts of metabolite J3 for spectroscopic characterization, a mutant was used (PpJT833) which is blocked in the step of ring cleavage of 2,3-dihydroxybenzoates. It excreted metabolite $\mathrm{J} 3$ with intermediate formation of 4-TFM-2,3-dihydro-2,3-dihydroxybenzoate. 


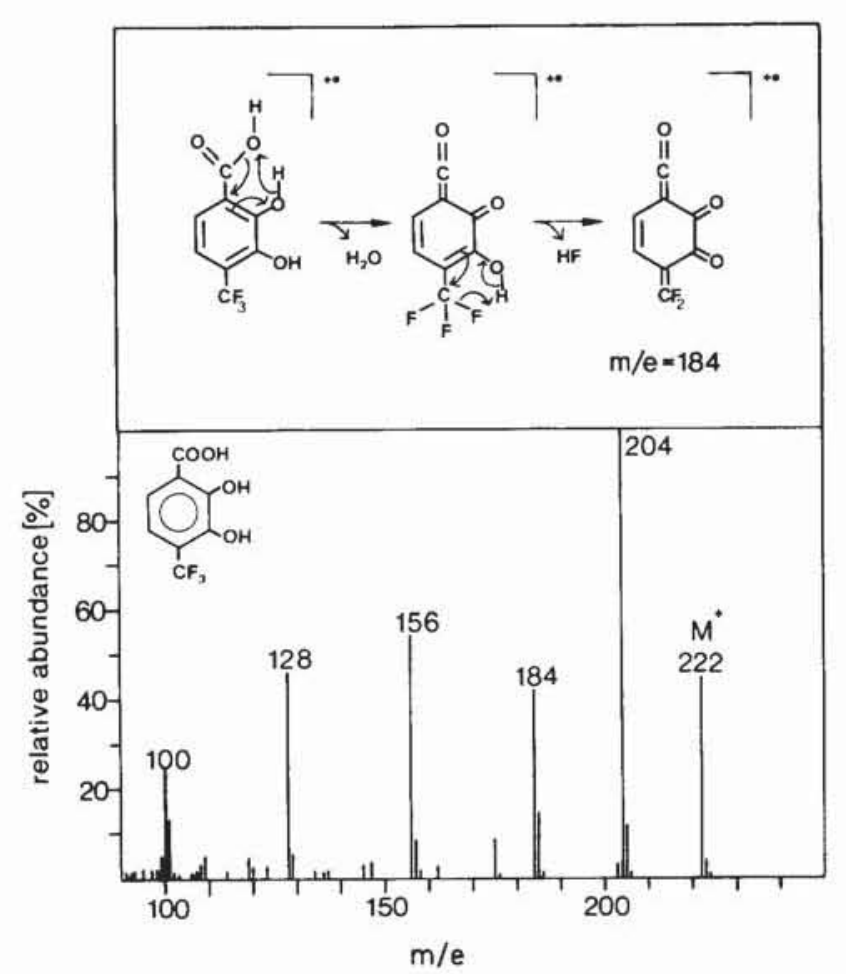

Fig. 3. Mass spectrum of 4-TFM-2,3-dihydroxybenzoate, the metabolite J3 of cometabolism of 4-TFM-benzoate by Pseudomonas putida JT101. For interpretation of the fragmentation pattern see text. Loss of water and hydrogen fluoride by migration of hydrogen via cyclic intermediates successively yields three molecules of carbon monoxide. The mass spectrometer was operated in the electron impact mode

Table 2. Analyis of fragmentation pattern of 4-trifluoromethyl-2,3dimethoxybenzoic acid methylester (metabolite J3) and the reference compound 2,3-dimethoxybenzoic acid methylester

\begin{tabular}{|c|c|c|}
\hline $\begin{array}{l}\text { Parental ion or } \\
\text { fragmentation } \\
\text { products }\end{array}$ & $\begin{array}{l}\text { 4-Trifluoromethyl- } \\
\text { 2,3-dimethoxy- } \\
\text { benzoic acid } \\
\text { methylester } \\
\text { (methylated } \\
\text { metabolite J3) }\end{array}$ & $\begin{array}{l}\text { 2,3-Dimethoxy- } \\
\text { benzoic acid } \\
\text { methylester }\end{array}$ \\
\hline $\mathrm{M}^{+}$ & $264(94)^{a}$ & $196(92)^{b}$ \\
\hline $\mathrm{M}^{+}-\mathrm{CH}_{3}$ & $249 \quad(5)$ & 181 (10) \\
\hline $\mathrm{M}^{+}-\mathrm{F}$ & $245 \quad(15)$ & - \\
\hline $\mathrm{M}^{+}-\mathrm{CH}_{3} \mathrm{O}$ & $233(93)$ & $165(100)$ \\
\hline $\mathrm{M}^{+}-\left(\mathrm{CH}_{3} \mathrm{O}+\mathrm{H}_{2}\right)$ & $231(100)$ & $163(92)$ \\
\hline $\mathrm{M}^{+}-\left(\mathrm{CH}_{3}+\mathrm{CO}\right)$ & $221 \quad(15)$ & - \\
\hline $\mathrm{M}^{+} 1-\left(\mathrm{CH}_{3}+\mathrm{CH}_{3} \mathrm{OH}\right)$ & $217 \quad(40)$ & $149 \quad(30)$ \\
\hline $\mathrm{M}^{+} 1-\left(\mathrm{CH}_{3} \mathrm{O}+\mathrm{H}_{2}+\mathrm{CO}\right)$ & $203 \quad(30)$ & $135 \quad(28)$ \\
\hline
\end{tabular}

The values for 2,3-dihydroxybenzoate are found in literature (Stenhagen et al. 1974; MS-Data-Centre 1974). For preparation of metabolite $\mathrm{J} 3$ see text

a. $b$ The values in parentheses give the relative intensities of peaks compared to $\mathrm{m} / \mathrm{e}=231^{\mathrm{a}}$ and $\mathrm{m} / \mathrm{e}=165^{\mathrm{b}}$

After extraction and purification as described in Materials and methods metabolite $\mathrm{J} 3$ was analyzed by means of mass spectroscopy (Fig. 3). The parental ion (p) ${ }^{+} \mathrm{m} / \mathrm{e}=222$ yielded the following major fragmentation products at $\left.\mathrm{m} / \mathrm{e}=204\left(\mathrm{p}-\mathrm{H}_{2} \mathrm{O}\right)^{+}, 184\left(\mathrm{p}-\mathrm{H}_{2} \mathrm{O}-\mathrm{HF}\right)^{+}\right), 156\left(\mathrm{p}-\mathrm{H}_{2} \mathrm{O}-\mathrm{HF}-\right.$
Table 3. Dioxygenation of 4-substituted benzoates by Pseudomonas putida JT101 and JT811

\begin{tabular}{lcc}
\hline Substrate & \multicolumn{2}{l}{$\begin{array}{l}\text { Relative activity (compared } \\
\text { to 4-isopropylbenzoate }=100)\end{array}$} \\
\cline { 2 - 3 } & Strain JT101 & Strain JT811 \\
\hline 4-Isopropylbenzoate & 100 & 100 \\
4-Ethylbenzoate & 78 & 78 \\
4-Trifluoromethylbenzoate & 31 & 33 \\
3-Trifluoromethylbenzoate & 4 & 5 \\
\hline
\end{tabular}

Strain JT101 was grown with 4-isopropylbenzoate, resuspended in $50 \mathrm{mM}$ phosphate buffer (pH. 7.4) to an optical density of $15(\lambda=$ $546 \mathrm{~nm})$ and incubated with benzoic acids $(3.3 \mathrm{mM})$. Substrate disappearance was followed by HPLC

Strain JT811 was grown with 4-ethylbenzoate and tested under the above mentioned conditions

$\mathrm{CO})^{+}, 128\left(\mathrm{p}-\mathrm{H}_{2} \mathrm{O}-\mathrm{HF}-\mathrm{CO}-\mathrm{CO}\right)^{+}$and $100\left(\mathrm{p}-\mathrm{H}_{2} \mathrm{O}-\mathrm{HF}-\mathrm{CO}-\right.$ $\left.\mathrm{CO}-\mathrm{CO})^{+}\right)$. This interpretation is based on the assumption of hydrogen migration events (Williams and Fleming 1975) as shown in Fig. 3, which allows multiple segregation of carbon monoxide.

The mass spectrum of fully methylated metabolite J3 was similar to 2,3-dimethoxybenzoate methylester and clearly distinguishable from other structural isomers (Table 2). The molecular ion peak at $\mathrm{m} / \mathrm{e}=264\left(\mathrm{p}^{+}\right)$of metabolite $\mathrm{J} 3$ is very intense ( $94 \%$ relative intensity). Fragment ions common to $\mathrm{J} 3$ and 2,3-dimethoxybenzoate methylester are due to loss of methylradical (m/e $=249$ and 181 resp.), methoxyradical (m/e $=233$ and 165 resp.) and both of methoxyradical and dihydrogen $(\mathrm{m} / \mathrm{e}=231$ and 163 resp.). With metabolite J3 additional loss of fluorine radical $(\mathrm{m} / \mathrm{e}=245)$ can be detected, a fragmentation pattern which is frequently observed with aromatics containing the TFM-group (Maier et al. 1978).

The proton magnetic resonance spectrum of permethylated metabolite $\mathrm{J} 3$ is easily interpreted: $\delta=3.9-4.0 \mathrm{ppm}$, $(9 \mathrm{H}, \mathrm{t}) \delta=7.3(1 \mathrm{H}, \mathrm{d}, \mathrm{J} 8.5 \mathrm{~Hz})$ and $\delta=7.5(1 \mathrm{H}, \mathrm{d}, \mathrm{J}$ $8.5 \mathrm{~Hz}$ ) are consistent with three non identical methylgroups and two adjacent aromatic protons. All these findings establish metabolite J3 as 4-TFM-2,3-dihydroxybenzoate.

Pseudomonas putida JT811 is a $p$-cumate degrading strain constitutively synthesizing a similar set of enzymes as Pseudomonas putida JT101 (Wigmore and Ribbons 1980, 1981). Cells of JT811 grown with glucose in a 11 -fermenter transformed 4-TFM-benzoate ( $3 \mathrm{mmol})$ thereby excreting 4-TFM-2,3-dihydro-2,3-dihydroxybenzoate $(0.6 \mathrm{mmol})$, 4-TFM-2,3-dihydroxybenzoate $(1.6 \mathrm{mmol})$ and 2-hydroxy6-oxo-7,7,7-trifluoro-hepta-2,4-dienoate $(0.5 \mathrm{mmol})$. No carboxylated species of the latter compound was observed.

The main product was the catechol-derivative 4-TFM2,3-dihydroxybenzoate. During this cooxidation, $90 \%$ of the metabolized substrate was accounted for by excreted metabolites. 4-TFM-benzoate did not inhibit turnover of 4-isopropylbenzoate at equimolar concentrations $(3.3 \mathrm{mM}$ each). This demonstrates poor binding of the fluorinated analogue. The relative reaction rates of differently substituted benzoates (Table 3) reveal a strong prevalence of the cumate dioxygenase for 4-substituted substrates: 3-TFMbenzoate is oxygenated very slowly whereas 4-TFMbenzoate shows a quite high turnover rate. 


\section{Kinetic constants for substrates and analogues}

Diol-dehydrogenase. The mutant Pseudomonas putida JT833 was used as a source of 2,3-dihydro-2,3-dihydroxybenzoate( $\mathrm{DHC})$-dehydrogenase. The block in the ring cleavage enzyme prevents disturbance of the enzyme assay by ring cleavage products of carboxycatechols (data not shown). At constant concentration of 4-isopropyl-2,3-dihydroxybenzoate (4-isopropyl-DHC) and varying concentrations of the NAD ${ }^{+}$the Michaelis constant of the coenzyme was estimated to be $37 \mu \mathrm{M}$.

The Michaelis constant for 4-isopropyl-DHC at saturating concentration of $\mathrm{NAD}^{+}$was calculated to be $17 \mu \mathrm{M}$. The binding of 4-TFM-2,3-dihydro-2,3-dihydroxybenzoate was calculated from its inhibitory effect on 4-isopropyl-DHC turnover $\left(K_{\mathrm{i}}=12 \mu \mathrm{M}\right)$. The inhibition was of competitive type. As the $K_{\mathrm{i}}$-value is defined as the dissociation constant of the enzyme-inhibitor complex, it can be deduced that 4-isopropyl- and 4-TFM-2,3-dihydrodihydroxybenzoate are bound equally well to DHC-dehydrogenase of Pseudomonas putida JT101. 3-Methyl-as well as 3-TFM-1,2-dihydroxy-2-hydro-benzoates which both differ slightly in molecular structure (1,2-dihydroxy-2-hydrobenzoate instead of 2,3 substituted ones; see preceding paper Engesser et al. 1988) are bound not at all.

Although 4-TFM-2,3-dihydro-2,3-dihydroxybenzoate is bound very well, its turnover rate compared to 4-isopropyl$\mathrm{DHC}$ is low (4\%). This explains the accumulation and excretion of 4-TFM-2,3-dihydro-2,3-dihydroxybenzoate into the medium during cometabolism of 4-TFM-benzoate by whole cells of Pseudomonas putida JT811.

\section{3,4-Dioxygenase (ring-cleavage enzyme)}

This enzyme is extremely sensitive against oxygen which is known to be a common property shared by most $\mathrm{Fe}^{2+}$ containing dioxygenases (Iwaki and Nozaki 1982).

Michaelis constants of 2,3-dihydroxybenzoate-3,4-dioxygenase as well as relative turnover rates at saturating concentrations of 4-substituted 2,3-dihydroxybenzoates are shown in Table 4. 4-TFM-2,3-dihydroxybenzoate shows an extremely strong binding $\left(K_{\mathrm{i}}=6 \mathrm{nM}\right)$ when compared with its fluorofree analogue 4-methyl-2,3-dihydroxybenzoate $\left(K_{\mathrm{m}}=7 \mu \mathrm{M}\right)$. Besides the fluorine substitution also the carboxylic group contributes to binding to the enzyme as is demonstrated by the thousandfold lowered affinity of 3-TFM-catechol $\left(K_{\mathrm{i}}=1.7 \mu \mathrm{M}\right)$. With both TFM-substrates inhibition was of competitive type. In spite of its strong binding, the maximum dioxygenation rate, however, for 4-TFM-2,3-dihydroxybenzoate is very low compared to 4-alkyl substituted substrates. This explains the accumulation and excretion of the side chain fluorinated analogue during cometabolism of 4-TFM-benzoate.

\section{Ring-cleavage product decarboxylase}

Extracts of mutant strain Pseudomonas putida 104 accumulated 3-carboxy-2-hydroxy-7-methyl-6-oxo-octa-2,4dienoate quantitatively from 2,3-dihydroxy-p-cumate (DeFrank and Ribbons 1977b). After completion of the reaction, however, the concentration of the product did not remain constant indicating a slow decarboxylation. The velocity of this decarboxylation reaction was nearly indepen-
Table 4. Relative maximum turnover rates and binding constants of substituted catechols for 2,3-dihydroxybenzoate-3,4-dioxygenase from Pseudomonas putida JT104

\begin{tabular}{llll}
\hline Assay substrate & $\begin{array}{l}\text { Assay } \\
\text { wave- } \\
\text { length } \\
{[\mathrm{nm}]}\end{array}$ & $\begin{array}{l}K_{\mathrm{m}}, K_{\mathrm{i}} \\
{[\mu \mathrm{M}]}\end{array}$ & $\begin{array}{l}\text { Relative } \\
\text { activity }\end{array}$ \\
\hline $\begin{array}{l}\text { 4-Isopropyl-2,3-dihydroxy- } \\
\text { benzoate }\end{array}$ & 345 & 1 & $100^{\mathrm{a}}$ \\
$\begin{array}{c}\text { 4-Methyl-2,3-dihydroxy- } \\
\text { benzoate }\end{array}$ & 340 & 7 & 205 \\
$\begin{array}{c}\text { 3-Trifluoromethyl-1,2- } \\
\text { dihydroxybenzene }\end{array}$ & 385 & $K_{\mathrm{i}}=1.7$ & 0.15 \\
$\begin{array}{c}\text { 4-Trifluoromethyl-2,3- } \\
\text { dihydroxybenzoate }\end{array}$ & 385 & $K_{\mathrm{i}}=0.006$ & 0.4 \\
\hline
\end{tabular}

The enzyme was assayed by following the increase of absorption of products at the respective wavelengths. For preparation of crude extracts as well as extinction coefficients see Material and methods. The dioxygenation of 4-trifluoromethyl-2,3-dihydroxybenzoate was assayed by following the increase of absorption of the decarboxylated reaction product, 2-hydroxy-6-oxo-7,7,7-trifluoro-hepta-2,4dienoate (see text)

- The reaction rates are expressed as percentages of that for 4-isopropyl-2,3-dihydroxybenzoate taken as $100 \%$

dent of the amount of added cell extract. A forty fold increase of extract only doubled the rate of decarboxylation $(\Delta \mathrm{E} / \mathrm{min}=0.008$ and 0.016 resp.). Inhibition experiments using phenol, p-chloromercuribenzoate and incubating the test mixture at strongly alkaline conditions in order to destroy a possible residual activity of the decarboxylase also pointed to a chemical decarboxylation reaction (data not shown). In all cases controls with the wild type extracts showed very rapid inactivation of decarboxylase enzyme. Decarboxylation of the ring cleavage product of 2,3-dihydroxy-p-cumate in extracts of the mutant Pseudomonas putida JT104 therefore seems to be non enzymatic.

During turnover by whole cells of 4-TFM-2,3-dihydroxybenzoate by meta cleaving 2,3-dihydroxybenzoate dioxygenase of mutant strain JT104 accumulation of the 3-carboxylated ring fusion product could not be observed; instead of this only the decarboxylated compound accumulated in the medium. Therefore, the TFM-group does not impede the decarboxylation reaction, but probably accelerates it. After complete turnover of 4-TFM-2,3-dihydroxybenzoate the molar extinction coefficient of the product 2-hydroxy-6-oxo-7,7,7-trifluoro-hepta-2,4-dienoate (7-TFHOD) was calculated to be $\varepsilon=27,500$ which agrees well with the value of $\varepsilon=26,900$ given in the preceding paper, (Engesser et al. 1988) but determined with other methods.

The accumulation of TFHOD is due to its negligible turnover rate with the hydrolase compared to nonfluorinated HOD and 7,7-dimethyl-HOD (Table 5). The binding, however, of the TFM-substituted substrate is excellent as revealed by a $K_{\mathrm{i}}$-value of $130 \mathrm{nM}$ (competitive inhibition). In this respect the enzyme behaves like the hydrolase from Pseudomonas putida mt-2 (Table 5). Substitution of the two methylgroups in 7,7-dimethyl-HOD by hydrogen reduces turnover rate in the cymene degrading strain Pseudomonas putida JT101 whereas in Pseudomonas putida $\mathrm{mt}-2$ it promotes the reaction rate. 
Table 5. Relative maximum turnover rates and binding constants of 6-substituted 2-hydroxymuconic semialdehydes for hydrolases in Pseudomonas putida $\mathrm{mt}-2$ and JT101

\begin{tabular}{|c|c|c|c|c|}
\hline \multirow[t]{2}{*}{ Substrate } & \multicolumn{2}{|c|}{$V_{\max \text { rel }}[\%]$} & \multicolumn{2}{|l|}{$K_{\mathrm{m}}[\mu \mathrm{M}]$} \\
\hline & JT101 & $\mathrm{mt}-2$ & JT101 & $\mathrm{mt}-2$ \\
\hline $\begin{array}{l}\text { 6-Methyl-2-hydroxy- } \\
\text { muconicsemialdehyd } \\
\text { (6-methyl-SA) }\end{array}$ & 10 & $100^{\mathrm{a}}$ & - & 8 \\
\hline $\begin{array}{l}\text { 6-Isopropyl-2- } \\
\text { hydroxymuconicsemi- } \\
\text { aldehyd (6-iso- } \\
\text { propyl-SA) }\end{array}$ & $100^{\mathrm{b}}$ & 7 & 2 & - \\
\hline $\begin{array}{l}\text { 6-Trifluoromethyl-2- } \\
\text { hydroxymuconicsemi- } \\
\text { aldehyd (6-tri- } \\
\text { fluoromethyl-SA) }\end{array}$ & 0.15 & 0.1 & $\begin{array}{l}K_{\mathrm{i}}= \\
130 \mathrm{nM}^{\mathrm{e}}\end{array}$ & $\begin{array}{l}K_{\mathrm{i}}= \\
300 \mathrm{nM}^{\mathrm{d}}\end{array}$ \\
\hline
\end{tabular}

The preparation of crude extracts is described in Material and methods

a, b The relative maximum turnover rates were determined at saturating substrate concentrations $(100 \mu \mathrm{M})$. They are expressed as percentages of that for 6-isopropyl-SA ${ }^{\mathrm{b}}$ and 6 -methyl-SA ${ }^{\mathrm{a}}$ taken as $100 \%$ in each case. $K_{\mathrm{m}}$-values were derived from LineweaverBurk plots. $K_{i}$-values were calculated from replots of the slopes of lines representing different inhibitor concentrations against the corresponding inhibitor concentration

- Concentration of 6-isopropyl-SA was varied

${ }^{d}$ Concentration of 6-methyl-SA was varied

\section{Discussion}

The detection of aromatics carrying the trifluoromethyl (TFM) group as substituents in river water (Lombardo 1979; Jungclaus et al. 1978; Maier et al. 1978) promoted us to investigate the effects of side chain fluorination on bacterial metabolism of aromatics using toluate degrading bacteria as model organisms (see preceeding paper, Engesser et al. (1988).

Dehydrogenation of TFM substituted 1,2-dihydroxy-2hydro-benzoates and hydrolysis of 2-hydroxy-6-oxo-7,7,7trifluoro-hepta-2,4-dienoate proved to be limiting reactions in Pseudomonas putida mt-2. Ortho-fission of 3-TFMcatechol was facile in the former strain but was critically restricted down in Rhodococcus rubropertinctus N657.

The influence of TFM groups on substrate binding of side chain fluorinated analogs varied considerably depending on the respective enzyme of the toluate pathway. In the present study similar observations were made using p-isopropylbenzoate ( $p$-cumate) and p-ethylbenzoate degrading Pseudomonas putida JT strains as model organisms. With the exception of the decarboxylase (Fig. 1) all enzymes investigated showed decreased turnover rates with substrates carrying a TFM-group instead of isopropyl.

As in the case of Pseudomonas putida mt-2, the initial enzyme, a non specific benzoate-2,3-dioxygenase shows some steric constraints masking electronic influences of substituents on reaction rates. Only 4-substituted substrates are dioxygenated with relative rates which are predicted by a Hammett-plot (Table 3). The low sensitivity factor derived from the Hammett-plot indicates a modest dependence only of the dioxygenation rate from the electron withdrawing character of the TFM-group. Accordingly, 4-TFM-benzoate

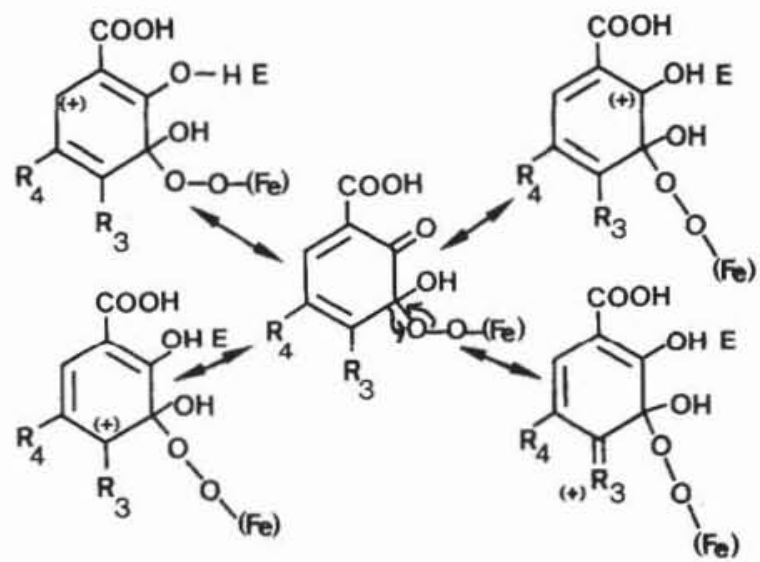

Fig. 4. Hypothetical scheme of stabilization of oxygen adduct in 2,3-dihydroxybenzoate-3,4-dioxygenase reaction by substituents $\mathrm{R}_{3}$. The arrows in the central formula denote the further rearrangements during the course of reaction. For details see text

is hydroxylated considerably slower than the bulkier 4-isopropylbenzoate definitely excluding sterical hindrance as a cause for the decrease of the reaction rate. The isomeric 3-TFM-benzoate, however, is dioxygenated at a rate $(1 / 20$ of cumate) which is far below the value expected from the Hammett-plot.

The inability of 4-TFM-benzoate to inhibit turnover of the bulkier $p$-cumate at equimolar concentrations is clearly not due to steric constraints. It may be the polarity of the substrate generated by the fluorine atoms of the TFM-group which do not allow proper binding to a possible hydrophobic side chain binding pocket of the cumate dioxygenase. In Pseudomonas putida $\mathrm{mt}$-2 for example, the 1,2-dihydroxy2-hydro-benzoate-dehydrogenase bound 4-chloro-1,2-dihydroxy-2-hydro-benzoate (4-chloro-DHB) ten times weaker than the bulkier 4-methyl-derivative (Engesser et al. 1988) indicating again other than steric effects to play an essential role.

The corresponding diol in Pseudomonas putida JT strain i.e. 4-TFM-2,3-dihydro-2,3-dihydroxybenzoate is readily bound. The turnover rate is very low causing excretion of this metabolite into the culture fluid during cometabolism of 4-TFM-benzoate. The reason for this may be the same as has been proposed to explain the low turnover rate of 3-TFM-1,2-dihydroxy-2-hydrobenzoate in Pseudomonas putida $\mathrm{mt}-2$ (Engesser et al. 1988). In this strain substitution of the methyl group in 3-methyl-DHB by fluorine, chlorine or bromine did not alter binding as well as turnover rates substantially. The TFM group possibly causes a drastic reduction of reaction rate through stabilization of an unsuitable conformere (see preceding paper, Engesser et al. 1988).

The next enzyme in the degradation sequence of p-cumate in strain Pseudomonas putida JT811 and 101 is a ring cleaving meta-pyrocatechase inserting two oxygen atoms in position 3 and 4 of 2,3-dihydroxybenzoates (DeFrank and Ribbons 1977b).

The reaction is strongly dependent on electron density at carbon atom 4 , and therefore on the electronic character of C-4-substituents, as is shown by a Hammett-plot (Fig. 6).

According to previously made suggestions (Engesser et al. 1988; Dorn and Knackmuss 1978; Hamilton 1974; Que 
<smiles>[2H]C(=O)/C(C)=C/C(=O)O</smiles><smiles>[3H][3H]</smiles>

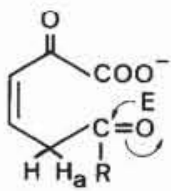<smiles>[3H][3H]</smiles>

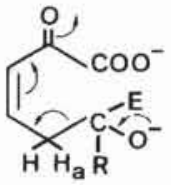<smiles>CC(=O)[I+]/C=C\C(=O)C(=O)[O-]</smiles>

Fig. 5. Hypothetical reaction scheme of HOD-hydrolases. The scheme is based on the stereochemistry of hydrogen at $\mathrm{C}_{5}$ which changes configuration during the course of reaction (Shaw et al. 1965). $E$ stand for a nucleophilic species of the enzyme or for hydroxylion. The endproducts are shown for 2-hydroxy-6oxohepta-2,4-dienoate as a substrate

jr et al. 1977) a model of the reaction mechanism can be adopted in which extensive delocalization of positive charge generated after attack of dioxygen is an essential feature (Fig. 4). This would explain the extremely reduced turnover rate of 4-TFM-2,3-dihydroxybenzoate as well as the very high reaction rate with 4-methoxyl-substituted 2,3-dihydroxybenzoate. The catechol-2,3-dioxygenase of Pseudomonas putida $\mathrm{mt}-2$ (Engesser et al. 1988) did not show such a strong dependence of reaction velocity of the methoxyl substituent which exerts a positive mesomeric effect. 4-TFM-2,3-dihydroxybenzoate binds to the enzyme extremely strong (Table 4). This is attributable not only to the TFM group but also to the carboxyl group as is shown by the threehundredfold increased Michaelis constant of 3-TFM catechol. The reason for the enhancing effect of the TFM group on substrate binding may be its acidifying influence on the phenolic hydroxyl groups of the catechol moiety. This assumption has been made already with a chlorocatechol cleaving pyrocatechase (Dorn and Knackmuss 1978).

Another metapyrocatechase from Pseudomonas putida was shown to bind 3-chlorocatechol tightly, although there was no turnover of this substrate (Kleckka and Gibson 1981). The metapyrocatechase from Pseudomonas putida mt-2 showed only very slow turnover with 3-chloro and 3-fluorocatechol concomitantly undergoing suicide inactivation

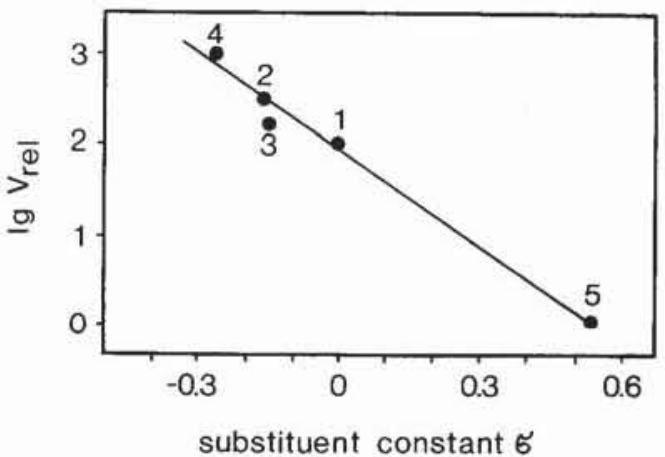

Fig. 6. Correlation between $\lg V_{\max }$-values of the 2,3-dihydroxybenzoate-3,4-dioxygenase reaction in Pseudomonas putida JT104 with 4-substituted 2,3-dihydroxybenzoates and the corresponding substituent constants. The $V_{\max }$-values are listed in Table 2, except of values for $\mathrm{R}=\mathrm{H}$ and $\mathrm{R}=\mathrm{OCH}_{3}$ which are derived from literature (DeFrank and Ribbons 1977b). The substituent constants have been published (Norman and Taylor 1965); 1 2,3dihydroxybenzoate; 2 4-methyl-2,3-dihydroxybenzoate; 3 4-isopropyl-2,3-dihydroxybenzoate; 4 4-methoxy-2,3-dihydroxy-benzoate; 5 4-trifluoromethyl-2,3-dihydroxybenzoate

(Bartels et al. 1984). The deactivating effect of electronegative substituents adjacent to the site of oxygen attak to catechols therefore seems to be a general phenomenon for metapyrocatechases.

The ring cleavage product of 4-TFM-2,3-dihydroxybenzoate is subject to spontaneous decarboxylation yielding 2-hydroxy-6-oxo-7,7,7-trifluoro-hepta-2,4-dienoic acid (7TFHOD). (This decarboxylation reaction seems to proceed fast enough even without decarboxylase enzyme indicating a non enzymatic reaction.) Obviously this non-enzymatic reaction is not hampered by substituents like fluorine.

The hydrolysis of 7-TFHOD would yield 2-hydroxypenta-2,4-dienoate and trifluoroacetic acid. In Pseudomonas putida mt-2 (Engesser et al. 1988) as well as in Pseudomonas putida JT101 the 7-TFHOD shows a high affinity to HOD hydrolase (Table 4). The turnover rates, however, are very low. To explain this phenomenon a reaction mechanism is presented (Fig. 5) which is based essentially on literature data (Shaw et al. 1965; Duggleby and Williams 1986; Duggleby 1979). Accordingly an isomerization step is thought to precede a hydration reaction which is followed by heterolysis of the bond between carbon atom 5 and 6 . Similar electron shifts have been proposed for processing other meta-ring cleavage products (Dagley 1978). The influence of the TFM-group on the nucleophilic attack on the carbonyl can be estimated from the well known tendency of carbonylic compounds, substituted with electronegative substituents, to form hydrates. Conversely electron-rich substituents favour the non hydrated species. The equilibrium constants of the hydration reaction decrease in the series formic aldehyde, acetaldehyde and aceton $\left(K=2 \cdot 10^{+3}, 1.4\right.$ and $2 \cdot 10^{-3} \mathrm{rsp}$.). Correspondingly trifluoroacetaldehydehydrate is so stable that it can not be dehydrated by a simple destillation (Braendlin and McBee 1963, Husted and Ahlbrecht 1952). It seems reasonable therefore, that the nucleophilic addition of XH $(x=\mathrm{OH}$ or an enzyme nucleophile) to the TFM group bearing carbon atom should be enhanced by the latter function. Conversely, however, the heterolysis of the carbon $\mathrm{C}_{5}-\mathrm{C}_{6}$ then may be severely retarded (Fig. 5) by electronegative substituents. 
For the HOD-hydrolase from Pseudomonas putida $\mathrm{mt}-2$ the turnover rates of 6-methyl-HMS are 1000-fold greater than of 6-TFM-HMS even though the $K_{\mathrm{m}}$-value of the latter substrate is about 25 -fold lower than that of the former. Since the proposed nucleophilic attack of $\mathrm{C}_{6}$ in the 6-TFMHMS should be facilitated, the dramatic decrease in turnover rate may be due to inhibition of the heterolysis of the $\mathrm{C}_{5}-\mathrm{C}_{6}$ bond by the electron withdrawing substituent (Fig. 5). Other substituents e.g. hydrogen, ethyl, alkyl, n-propyl and isopropyl have similar $K_{\mathrm{m}}$ - or $K_{\mathrm{i}}$-values to 6-methyl-HMS, but they also show diminished turnover rates (Duggleby and Williams 1986; Table 5).

This implies that the size of the 6-substituent can also affect the heterolysis of the $\mathrm{C}_{5}-\mathrm{C}_{6}$ bond. This hypotheses are difficult to test, as substitution of the TFM-group as a probe for electronegative substituents by others like chlorine or fluorine directly attacked to the carbonyl-carbon would create acylhalides. These very reactive compounds lead to suicidal destruction of enzymes (Bartels et al. 1984).

Whether other HOD hydrolases are also so extremely sensitive against fluorine substitution in 2-hydroxy-6-oxo7,7,7-trifluorohepta-2,4-dienoate is under current investigation. First results are pointing in this direction.

Acknowledgement. We would like to thank H.-J. Knackmuss, Institut für Mikrobiologie der Universität Stuttgart, FRG, for many helpful discussions. We gratefully acknowledge the following for spectral and analytical services: G. Remberg and U. Leonhard, Universität Göttingen, Göttingen, FRG, for mass and NMR spectrometry.

\section{References}

Ali DA, Callely AG, Hayes M (1962) Ability of a vibrio grown on benzoate to oxidize para-fluorobenzoate. Nature 196:194-195

Bartels J, Knackmuss HJ, Reineke W (1984) Suicide inactivation of catechol-2,3-dioxygenase from Pseudomonas putida $\mathrm{mt}-2$ by 3-halocatechols. Appl Environ Microbiol 47:500-505

Bialek J (1962) Decarboxylation of lutidinic and isocinchomeronic acids in ammonium bisulphate. Bull Acad Polon Science 10:625-627

Braendlin HP, McBee ET (1963) Effects of adjacent perfluoroalkyl groups on carbonyl reactivity. Adv Fluorine Chem 3:1-18

Clarke KF, Callely AG, Livingstone A, Fewson CA (1975) Metabolism of monofluorobenzoates by Acinetobacter calcoaceticus NCIB 8250: formation of monofluorocatechols. Biochim Biophys Acta 404:169-179

Dagley S (1978) Pathways for the utilization of organic growth substrates. In: Gunsalus LC (ed) The bacteria, vol VI. Academic Press, New York, pp 305-388

DeBoer TJ, Backer HJ (1954) A new method for the preparation of diazomethane. Rec Trav Chim 73:229-234

DeFrank JJ, Ribbons DW (1976) The p-cymene-pathway in Pseudomonas putida $\mathrm{PL}$ : isolation of a dihydrodiol accumulated by a mutant. Biochem Biophys Res Commun 70:1129-1195

DeFrank JJ, Ribbons DW (1977 a) p-Cymene-pahway in Pseudomonas putida: initial reactions. J Bacteriol 129:1356-1364

DeFrank JJ, Ribbons DW (1977b) p-Cymene-pathway in Pseudomonas putida: ring cleavage of 2,3-dihydroxy-p-cumate and subsequent reactions. J Bacteriol 129:1365-1374

Dorn E, Knackmuss HJ (1978) Chemical structure and biodegradability of halogenated aromatic compounds: substituent effects on 1,2-dioxygenation of catechol. Biochem J 174:8594

Duggleby CJ (1979) Studies on some enzymes involved in the metacleavage of catechol. Ph Thesis Dep Biochem Soil Sci Bangor, Wales
Duggleby CJ, Wiliams PA (1986) Purification and some properties of the 2-hydroxy-6-oxohepta-2,4-dienoate hydrolase (2-hydroxymuconic semialdehyde hydrolase) encoded by the TOL plasmid pWWO from Pseudomonas putida $\mathrm{mt}-2$. J Gen Microbiol 132:717-726

Engesser KH, Cain RB, Knackmuss HJ (1988) Bacterial metabolism of side chain fluorinated aromatics: cometabolism of 3-trifluoromethyl(TFM)-benzoate by Pseudomonas putida (arvilla) mt2 and Rhodococeus rubropertinctus N657. Arch Microbiol 149:188-197

Goldman P, Milne GWA, Pignataro MT (1967) Fluorine containing metabolites formed from 2-fluorobenzoic acid by Pseudomonas species. Arch Biochem Biophys 118:178-184

Hamilton GA (1974) Chemical models and mechanisms for oxygenases. In: Hayaishi $\mathrm{O}$ (ed) Molecular mechanisms of oxygen activation. Academic Press, New York, pp 405-451

Harper DB, Blakley ER (1971) The metabolism of p-fluorobenzoic acid by a Pseudomonas sp. Can J Microbiol 17:1015-1023

Hartmann J, Reinecke W, Knackmuss HJ (1979) Metabolism of 3-chloro-,4-chloro- and 3,5-dichlorobenzoate by a pseudomonad. Appl. Environm Microbiol 37:421 - 428

Husain M, Entsch B, Ballou DP, Massey V, Chapman PJ (1980) Fluoride elimination from substrates in hydroxylation reactions catalyzed by p-hydroxybenzoate hydroxylase. J Biol Chem 255: $4189-4197$

Husted DR, Ahlbrecht AH (1952) The chemistry of perfluoro acids and their derivates. J Am Chem Soc 74:5422 - 5426

Iwaki M, Nozaki M (1982) Immobilization of metapyrocatechase and its properties in comparison with the soluble enzyme. J Biochem 91:1549-1553

Jungclaus GA, Lopez-Avila V, Hites RA (1978) Organic compounds in an industrial wastewater: a case study of their environmental impact. Environm Sci Techn 12:88-96

Kleĉka GM, Gibson DT (1981) Inhibition of catechol 2,3-dioxygenase from Pseudomonas putida by 3-chlorocatechol. Appl Environ Microbiol 41:1159-1165

Lombardo P (1979) FDA's chemical contaminants program: the search for the unrecognized pollutant. In: Nicholson WJ, Moore JA (eds) Health effects of halogenated aromatic hydrocarbons, vol 320. New York Acad of Science, New York, pp $673-677$

Maier EJ, Fritschi G, Kussmaul H (1978) Identifizierung von Fluorkohlenwasserstoffen im Main mittels Gaschromatographie-Massenspektrometric. Vom Wasser 51:227-234

Meyer R (1883) Untersuchungen über Hydroxylierung durch direkte Oxydation. Annal Chem 219:234-250

Milne GWA, Goldman P, Holtzman JL (1968) The metabolism of 2-fluorobenzoic acid. II. Studies with ${ }^{18} \mathrm{O}_{2}$. J Biol Chem $243: 5374-5376$

MS-Data-Centre (1974) Eight peak index of mass spectra, 2nd edn. Mass Spectrometry Data Centre Reading, p 274

Norman ROC, Taylor R (1965) Electrophilic substitution in benzenoid compounds. Elsevier, Amsterdam

Que Jr L, Lipscomb JD, Münck E, Wood JM (1977) Protocatechuate 3,4-dioxygenase inhibitor studies and mechanistic implications. Biochim Biophys Acta 485:60-74

Reineke W, Knackmuss HJ (1978a) Chemical structure and biodegradability of halogenates aromatic compounds. Substituent effects on 1,2-dioxygenation of benzoic acids Biochim Biophys Acta 542:412-423

Reineke W, Knackmuss HJ (1978b) Chemical structure and biodegradability of halogenated compounds. Substituent effects on dehydrogenation of 3,5-cyclohexadiene-1,2-diol-1carboxylic acid. Biochim Biophys Acta 542:424-429

Shaw DA, Borkenhagen LF, Talalay P (1965) Enzymatic oxidation of steroids by cell-free extracts of Pseudomonas testosteroni: isolation of cleavage products of ring a. Proc Nat Acad Sci $54: 837-844$

Smith A, Trauter EK, Cain RB (1968) The utilization of some halogenated aromatic acids by Nocardia. Biochem J 106:203209 
Stenhagen E, Abrahamsson S, McLafferty FW (1974) Registry of mass spectral data, vol 2. John Wiley, New York, p 937

Wessely F, Benedikt K, Benger H, Friedrich G, Prillinger F (1950)

Zur Kenntnis der Carboxylierung von Phenolen. Monatsh Chem 81:1071-1091

Wigmore GJ, Ribbons DW (1980) p-Cymene pathway in Pseudomonas putida: defective mutants by using selective enrichment of halogenated substrate analogs. J Bacteriol 143:816-824
Wigmore GJ, Ribbons DW (1981) Selective enrichment of Pseudomonas spp defective in catabolism after exposure to halogenated substrates. J Bacteriol 146:920 - 927

Williams DH, Fleming J (1975) Spektroskopische Methoden der Strukturaufklärung. Thieme, Stuttgart, pp 162-216

Received June 11, 1987/Accepted October 30, 1987 